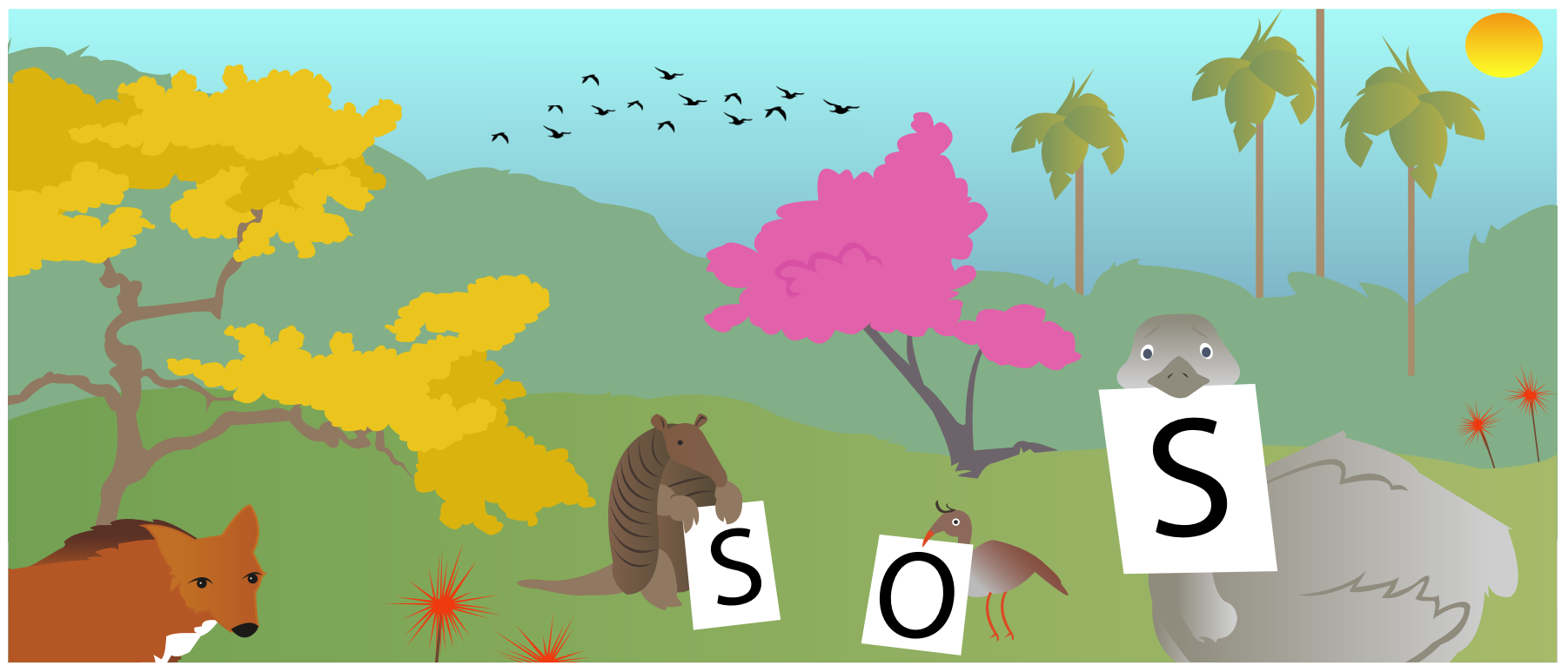

\title{
THE CERRADO BIOME: A FORGOTTEN BIODIVERSITY HOTSPOT
}

\section{Gabriel Damasco ${ }^{*}$, Clarissa Fontes ${ }^{1}$, Renata Françoso ${ }^{2}$ and Ricardo Haidar ${ }^{3}$ \\ ${ }^{1}$ University of California, Berkeley, Berkeley, CA, United States, IInstituto Federal de Brasília, Brasilia, Brazil, ${ }^{3}$ Departamento de Ecologia, Universidade de Brasília, Brasilia, Brazil}

\section{REVIEWED BY: \\ GUELPH MONTESSORI $S C H O O L$ AGE: 9-11}

\section{BIOME}

A large ecological area on the earth's surface, with fauna and flora (animals and plants) adapting to their environment.

A biome also defined by its non-living factors, such as climate, geology, soil, and vegetation.
Have you heard of the Cerrado biome? Do you know what a biodiversity hotspot is? In this article, you will learn why we should care about the biodiversity in the Cerrado biome. A biome is a community of plants and animals in a large area that shares the same climate and habitat features. Tropical biomes have the greatest diversity of plants and animals on the planet. However, when it comes to tropical biodiversity, people are quick to think of the Amazon. The Cerrado has a great biodiversity that is just as important to conserve as the Amazon Biome. However, the Cerrado continues to be forgotten and neglected, leading to the devastation of its natural areas. Let us learn more about this fantastic biome and help us spread the word about the urgency of preserving the Cerrado!

\section{INTRODUCTION}

What is the Cerrado? The Cerrado is a vast tropical biome composed of savannas and grasslands amid humid and dry forests. In Spanish, the word cerrado means closed, shut, thick or dense, but in Brazil, the word has been used 
to describe an arid ecosystem and all the native species that are adapted to live in its seasonally variable climate. Where is the Cerrado? The Cerrado is located in the highlands of Central Brazil and covers about 2 million $\mathrm{km}^{2}$ or $21 \%$ of the Brazilian territory. It represents the second largest biome in South America, after the Amazon. The total area is equivalent to the size of Germany, France, England, Italy, and Spain all combined. Why is the Cerrado a hotspot of biodiversity? To be classified as a biodiversity hotspot, a region must have a high number of organisms that are not found anywhere else on earth. Also, the region must be in danger of being destroyed and have less than $30 \%$ of its natural vegetation. A hotspot, in other words, has an irreplaceable biodiversity. The Cerrado has over 4,800 species of plants and vertebrates (animals with backbones) found nowhere else on the planet. However, this extraordinary biodiversity is in danger because of the misconduct of political leaders and the lack of knowledge of our society.

\section{THE RICHEST SAVANNA IN THE WORLD}

The Brazilian Cerrado encompasses the most extensive woodland-savanna in South America (Figure 1). Woodland savannas are landscapes with scattered trees and shrubs forming a sparse canopy. The Cerrado region also has a great variety of habitats, from vast grasslands to dry-canopy forests [1]. Humid forests are also found along streams and rivers as green corridors (or gallery forests) throughout the landscape. Each of these unique habitats has different groups of plants, vertebrates, insects, and microorganisms that are adapted to live there. This variability of the environment makes the Cerrado one of the richest of all tropical savannas [2].

The Cerrado has more than 12,000 plant species, about 4,000 of which only exist in the Cerrado, including almost all of the herbs and short plants. When a plant exists only in a given location and nowhere else in the world, we say it

ENDEMIC

The situation in which a species is restricted to a particular region and found nowhere else on the planet. is "endemic" to that location. Some of the most unique plants in the Cerrado include a giant palm tree called "buriti" (Figure 2A) that grows only in swampy grasslands and forests. This tree is important to many birds for nesting and food and one of the most emblematic birds that nests on this palm is the bluethroated macaw (Figure 2B). This species forms permanent lifelong couples as they travel across the palm swamp after the buriti fruits. Also, tapirs, peccaries, fish, and monkeys depend on buriti fruits as their main food source. It is astonishing, how many animals are connected with the existence of a single plant. In terms of beauty, there are magnificent trees and shrubs coloring the landscape of Cerrado, such as the roble or trumpet trees (Figure 2C), which have a beautiful bloom of brilliant pink-, yellow-, white-, and purple-colored flowers. The "cigana-do-Cerrado" is a popular shrub because it stands out in the savannas with its strong reddish color (Figure 2D). 


\section{FIGURE 1}

An image of the Cerrado region showing the amount of natural vegetation that remains intact (green), the location and size of the national protected areas (yellow and red), and the total deforested area (pink). You can see that the Cerrado region covers a big area of the Brazilian territory. Unfortunately, only a tiny amount (less than $3 \%$ of the area) is currently protected by law. Source: Françoso et al. [3].

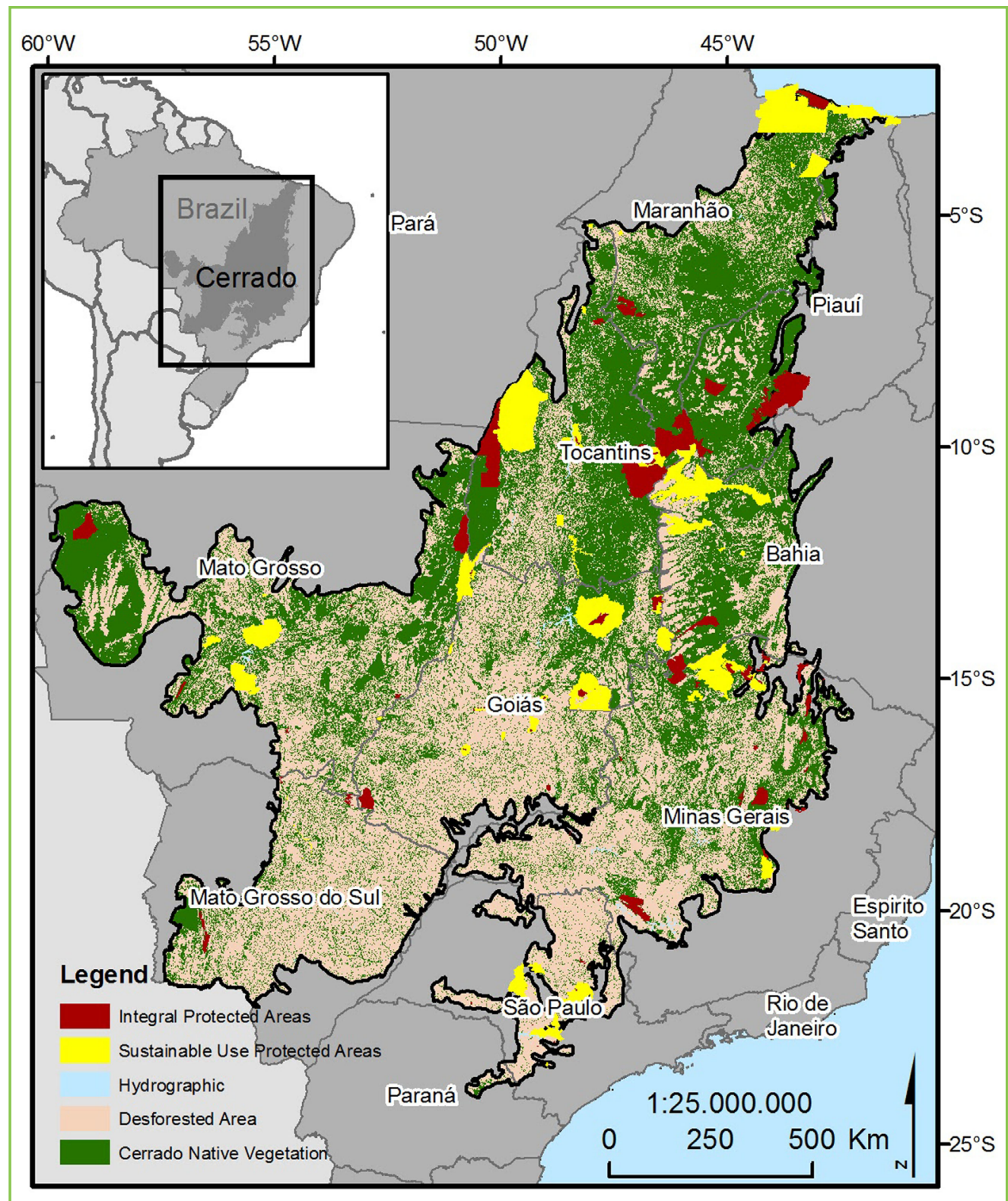

FIGURE

Around 20,000 years ago, large mammals, also known as megafauna, lived together with primitive humans in the Cerrado region. Many fossils of giant armadillos and giant sloths have been found here. A fossil is a remain or impression of a prehistoric organism preserved in petrified form or cast in rock. Nowadays, the Cerrado is still the main habitat of many rare large living mammals. One of the rarest mammal species is the maned wolf(Figure 2E), a golden-red, large-eared, and long-legged fox-like animal that can grow to $2.7 \mathrm{ft}$ in height and weigh about 50 pounds. Two of the most remarkable mammals in the region are the giant armadillo (Figure 2F) and the giant anteater (Figure 2G), the largest anteater in the world. When the armadillo feels the danger, its defense is to fold its body by tucking their head and legs into a shell and wait until the threat leaves. The giant anteater grows up to $7 \mathrm{ft}$ in length from the nose to the base of its tail, which is enormous and flag-like. Anteaters 


\section{FIGURE 2}

Examples of the extraordinary diversity of species and habitats found in the Cerrado.

A. A natural habitat of the "buriti" palm (scientific name: Mauritia flexuosa) growing in swampy grasslands; B. The blue-throated macaw (scientific name: Ara glaucogularis), one of the most emblematic birds in the Cerrado; C. The magnificent roble or trumpet trees in the genus Tabebuia, which have a beautiful bloom of brilliant pink-, yellow-, white-, and purple-colored flowers; D. The "cigana-do-Cerrado" (Caliandra dysantha) is a well-known shrub because it stands out in the savannas with its strong reddish color, which stands out in the savannas with its strong reddish color; E. The maned wolf (Chrysocyon brachyurus), a golden-red, large-eared, and longlegged fox-like mammal;

F. The giant armadillo (Priodontes maximus) that folds its body into a shell when it feels threatened;

G. The giant anteater (Myrmecophaga tridactyla) that grows up to $7 \mathrm{ft}$ in length from the nose to the base of its tail; $\mathbf{H}$. The blue-eyed ground dove (Columbina cyanopis) and the I. "minas-gerais" tyrannulet (Phylloscartes roquettei) listed as highly threatened on the IUCN Red List; J. Some of the largest birds in South America include the red-legged "seriema" (Cariama cristata); K. The rhea (Rhea americana);

L. One of the strangest reptiles is the giant worm lizard (Amphisbaena alba);

M. The coral snake group (Apostolepis sp.), that

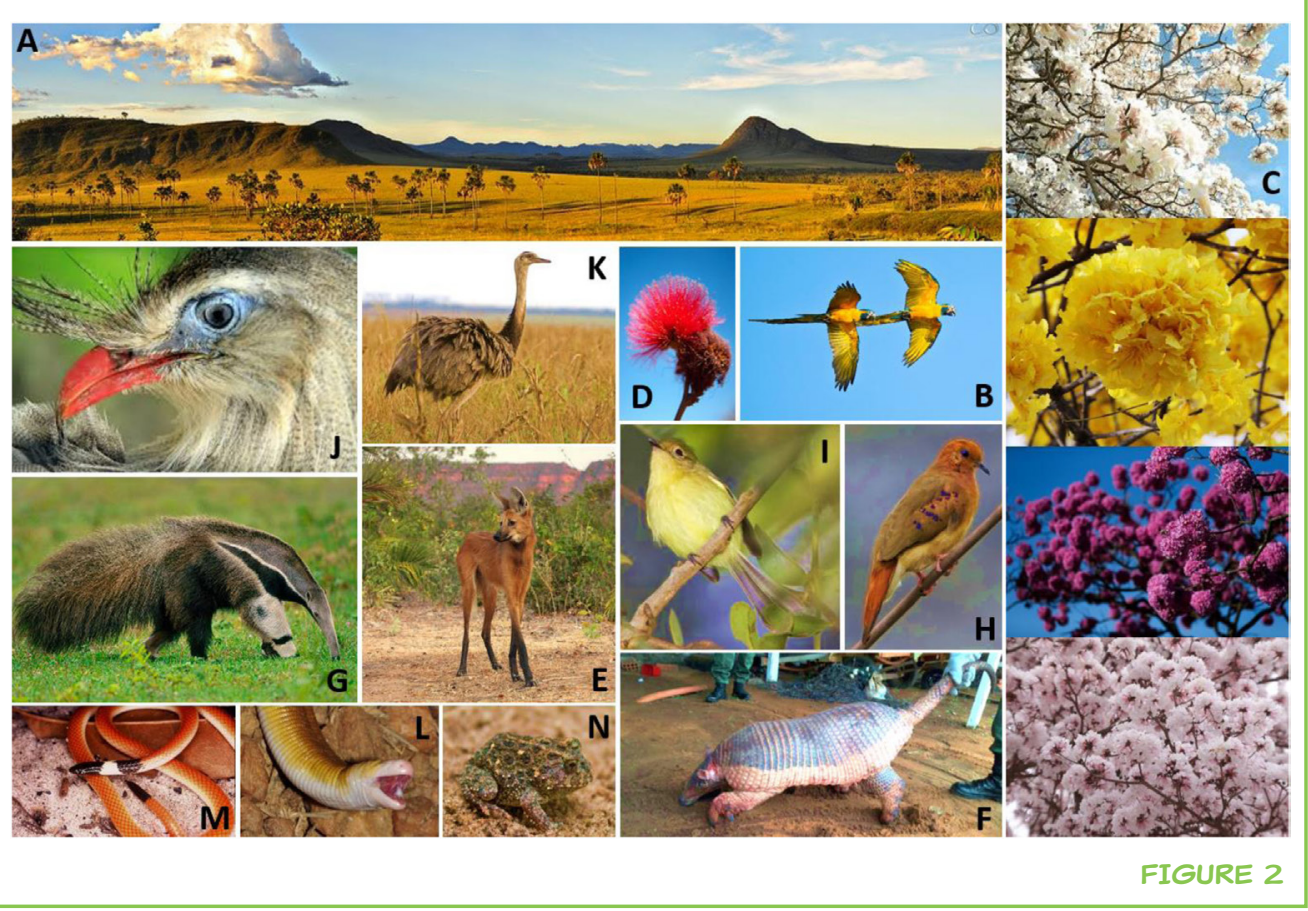

have a feeding strategy of licking up tons of ants and termites as quickly as possible. The anteater's tongue is covered with thousands of tiny hooks which are used to hold the insects together with large amounts of saliva. The giant anteater has to visit up to 200 nests per hour to consume the thousands of insects it needs to satisfy its hunger.

Regarding bird diversity, the Cerrado has more than 800 bird species, of which nearly 20 are endemic. Some birds species are listed as highly threatened on the IUCN Red List, like the blue-eyed ground dove (Figure $2 \mathrm{H}$ ) and the "minasgerais" tyrannulet (Figure 2I). Many bird watchers visit the Brazilian Cerrado because of the extraordinary bird diversity. Some of the larger birds in South America include the red-legged "seriema" (Figure 2J) and the greater rhea (Figure $2 \mathrm{~K}$ ), which are the largest birds on the continent. The rhea males are the ones who take care of the babies. They eat mostly fruits, invertebrates, and small vertebrates, like lizards, snakes, and rodents. The insect diversity of the Cerrado is far from being completely discovered. Scientists suggest that there are more than 50,000 species including butterflies, moths, termites, wasps, and bees waiting to be discovered in the region.

One of the strangest reptiles is the giant worm lizard (Figure 2L). It can grow up to $3 \mathrm{ft}$ in length and feeds on ants, beetles, and spiders. Of the other reptile species, 30 of 220 are considered endemic in the Cerrado, including 6 species of coral snakes (Figure 2M). The amphibians are extremely threatened because of the water pollution. An example of such a threatened species is the rocket frog (Figure $2 \mathrm{~N}$ ), that is found in only a few places in the biome. A recent threat to the amphibians in the Cerrado is a very powerful fungus (Batrachochytrium dendrobatidis, known as "Bd") that is responsible for the global decline and 
FIGURE 2

CONTINUED

includes six endemic species in the Cerrado;

N. An example of threatened frog species in the Cerrado

(Odontophrynus moratoi).

\section{IUCN RED LIST}

The world's most complete list of the conservation status of plants and animals. It evaluates the extinction risk of thousands of populations and species. This list is maintained by the International Union for Conservation of Nature.

\section{EXTINCTION}

The disappearance of a species of living organisms. Extinction usually occurs because of changed conditions to which the species is not suited. If no member of the affected species survives and reproduces, the entire species dies out. extinction of frog populations. The Bd was first reported in the Cerrado region in 2013 attacking two species of frogs. Amphibians breathe and take up water through their skin, and since the Bd fungus infects the frog skin, the infected frog can no longer breathe normally. In a period of a few months, the frog population can go from abundant to nearly non-existent.

The great biodiversity is not the only highlight of the Cerrado. This biome is the most humid savanna in the world. Water that evaporates in the Amazon is brought to the Cerrado by the wind. Moisture is very important, because it determines the wet season in the area. The rainfall during the wet season is the water supply of many rivers that harbor a total of 800 species of fish, nearly 200 of which are found only in the Cerrado. The rainfall is also a vital source of water for food crops and millions of people in South America.

\section{A WATER FOUNTAIN IN SOUTH AMERICA}

In the heart of Brazil, the Cerrado is the water fountain of the most important rivers in South America: the Tocantins, Paraná-Paraguay, and São Francisco rivers. Scientists also consider the Cerrado to be "the cradle of waters" since it hosts three large aquifers, which are underground water reservoirs. The aquifers are similar to large pools or tanks that store the water at very deep underground layers. The roots of plants in the Cerrado are deep and larger than their canopies, so the root systems are responsible for absorbing rainwater and transporting it to the aquifers. Due to deforestation (cutting down the forests), the plants have stopped bringing water to the deeper soil regions, and the aquifers have stopped supplying many of the water springs in the area. Scientists believe that the amount of water in these aquifers has already reached its minimum level. Therefore, the protection of the Cerrado is urgent to ensure the maintenance of the water resources during climate change.

\section{HOW DO PLANTS IN THE CERRADO DEAL WITH DROUGHT AND FIRE?}

Did you know that the roots of trees native to the Cerrado can grow up to three times the size of their trunks? Dry and seasonal climate have influenced the Cerrado for thousands of years. From October to April, the region can receive 1,100 and $1,600 \mathrm{~mm}$ of rainwater, but the rest of the time it is as arid as a desert, and the plants and animals must be able to survive in these extremely dry conditions. In rain-poor environments, the most interesting survival strategy developed by trees is called water redistribution. During the driest period, the tree's main root dives deeper into the ground in search of water that is left from the rainy season. The main root brings the water to the surface roots, which in turn redistribute the water to the top layers of the soil. As a natural water pump that redistributes the water between the deep 


\section{FIGURE 3}

Some examples of fire adaptations acquired by native plants in the Cerrado. A.,B. Thick and corky bark, $\mathbf{C}$. Re-sprouting capacity after fire; D. Example of a fire event in the Brazilian Cerrado savannas; E. Leathery and rough leaves; F. Super bloom events after fire.

\section{ADAPTATION}

Change or the process of change by which an organism or species becomes better suited to its environment.

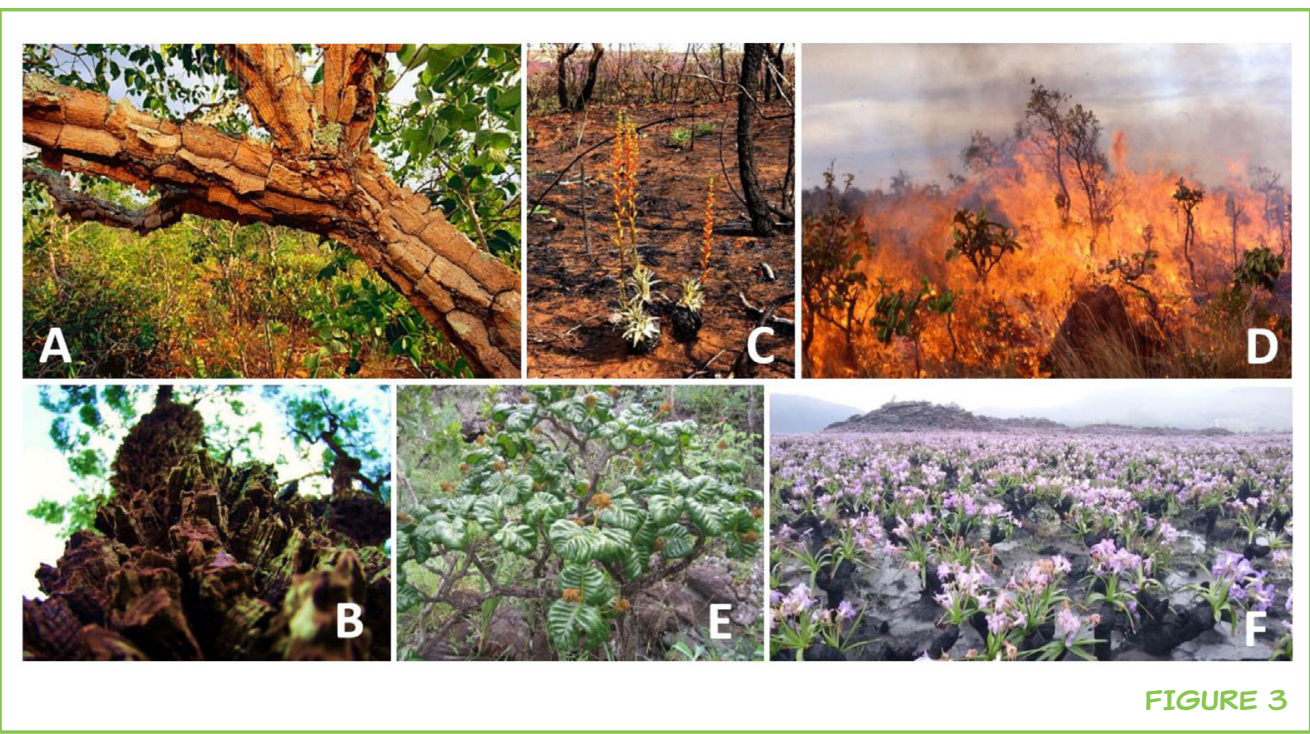

soils and the shallow roots, this mechanism is a necessary adaptation used by many trees in the Cerrado. With the arrival of the rainy season, the situation reverses: the surface roots absorb rainwater and transfer the water to the main root, which stores it several meters below the surface.

Fire is also part of the ecology in the Cerrado, and the plants there have numerous adaptations to fire, including corky bark to protect them from the heat, leathery and waxy leaves that resist wilting and water loss, and the ability to resprout very quickly after a fire, due to their deep root systems (Figure 3). Regular fires in this area help the nutrients to be recycled into the soil, benefit dormant seeds to sprout and stimulate certain flowers to bloom.

\section{THE NATIVE PEOPLE OF THE CERRADO}

Not only plants have adapted to live in the Cerrado but also humans have occupied the Cerrado over 12,000 years; and there is a rich mosaic of cultural heritage. The historical knowledge of these people represents an important layer of the biodiversity in the Cerrado. The Cerrado is home to 216 Indigenous (native people of South America) territories and 83 different ethnic groups. However, many of these communities cannot defend their ownership of the land, which has been one of the factors threatening the extinction of many tribes. The right to live and work on the land of the Cerrado is very important for these groups since it allows them to access essential resources necessary for their survival and their traditional ways of life.

Selling products manufactured by local communities in the Cerrado is a good way for the people living there to support themselves. Some of these products have been gaining popularity in the public markets. Fruit products 
such as "baru" nuts (Dipteryx alata), "pequi" (Caryocar brasiliensis), "jatobá" (Hymenaea stigonocarpa) flour, "açaî" (Euterpe edulis) berry, and "buriti" (Mauritia flexuosa) jam, as well as cosmetics and medicinal products, help to support the economy of the Cerrado people and help conserve its biodiversity. Ancient methods of farming and making products from plants are important allies in the protection of the Cerrado, as they help to assure the continuity of the natural resources for the future generations.

\section{THE FUTURE OF THE CERRADO}

The Cerrado is not nearly as recognized as the Amazon, but it is equally or even more important in terms of biodiversity. In the Cerrado, the National Parks cover only $7.5 \%$ of the natural biome area (Figure 1), whereas in the Amazon they cover $46 \%$ of the area. A vast area of the Cerrado is used for agriculture [4]. Since the demand for food production is predicted to rise steeply over the coming decades, it is likely that the Cerrado's native vegetation will gradually be replaced by pasture and farmlands. That replacement is very worrisome, as many of the Cerrado's plants and animals are likely to die with this change in land use [5]. Another urgent threat is the global climate change. The temperature is rising, and the rainfall is decreasing in the Cerrado region. These ongoing changes have already affected several species that depend on the outside temperature to regulate their own body temperature, such as lizards and amphibians. Moreover, if there is no adjustment in the speed and magnitude of the deforestation caused by agriculture, scientists are expecting a catastrophic extinction event in the next few years [6].

More conservation of the Cerrado is urgently needed. It is vital for the Brazilian society to come together to try to protect the Cerrado. It is also essential that conservation strategies are focused on conserving the biodiversity, preventing deforestation, and safeguarding the areas rich in endemic plants and animals. Do not let the Cerrado be forgotten! Help us to spread the word about the beauty and importance of this biome, one of the most fascinating biodiversity hotspots in the world.

\section{ACKNOWLEDGMENTS}

We thank Reuber Brandão for his insightful comments that enhanced the quality of the manuscript early versions. We are thankful for the suggestions offered by all young reviewers from Guelph Montessori School and Christina M. Caruso for leading the review with the students. We also thank the staff from Frontiers for Young Minds, in particular the Journal Manager Emma Clayton and the Journal Development Specialist Hedwig Ens for their careful reviewing assistance and English proofread. 


\section{REFERENCES}

1. Ratter, J. A., Ribeiro, J. F., and Bridgewater, S. 1997. The Brazilian Cerrado vegetation and threats to its biodiversity. Ann. Bot. 80(3):223-30. doi:10.1006/ anbo.1997.0469

2. Klink, C. A., and Machado, R. B. 2005. Conservation of the Brazilian Cerrado. Conserv. Biol. 19(3):707-13. doi:10.1111/j.1523-1739.2005.00702.x

3. Françoso, R. D., Brandão, R., Nogueira, C. C., Salmona, Y. B., Machado, R. B., and Colli, G. R. 2015. Habitat loss and the effectiveness of protected areas in the Cerrado Biodiversity Hotspot. Natureza Conservação 13(1):35-40. doi:10.1016/j. ncon.2015.04.001

4. Marris, E. 2005. Conservation in Brazil: the forgotten ecosystem. Nature 437(7061):944-5. doi:10.1038/437944a

5. Strassburg, B. B., Brooks, T., Feltran-Barbieri, R., Iribarrem, A., Crouzeilles, R., Loyola, R., et al. 2017. Moment of truth for the Cerrado hotspot. Nat. Ecol. Evol. 1:99. doi:10.1038/s41559-017-0099

6. Strassburg, B. B., Latawiec, A., and Balmford, A. 2016. Brazil: urgent action on Cerrado extinctions. Nature 540(7632):199. doi:10.1038/540199a

SUBMITTED: 22 September 2017; ACCEPTED: 07 May 2018;

PUBLISHED ONLINE: 25 June 2018.

EDITED BY: Ana Maria Rocha De Almeida, California State University, East Bay, United States

CITATION: Damasco G, Fontes C, Françoso R and Haidar R (2018) The Cerrado Biome: A Forgotten Biodiversity Hotspot. Front. Young Minds 6:22. doi:10.3389/frym.2018.00022

CONFLICT OF INTEREST STATEMENT: The authors declare that the research was conducted in the absence of any commercial or financial relationships that could be construed as a potential conflict of interest.

COPYRIGHT ( 2018 Damasco, Fontes, Françoso and Haidar. This is an open-access article distributed under the terms of the Creative Commons Attribution License (CC BY). The use, distribution or reproduction in other forums is permitted, provided the original author(s) and the copyright owner are credited and that the original publication in this journal is cited, in accordance with accepted academic practice. No use, distribution or reproduction is permitted which does not comply with these terms.

\section{REVIEWED BY}

\section{GUELPH MONTESSORI SCHOOL, AGE: 9-11}

We are an upper elementary class of 9- to 11-year-old students. We live in a small city in Ontario, Canada. We are eco-friendly and enjoy learning about science, math, history, culture, and art. Our two favorite things about being young reviewers were learning how to edit a science story for kids and how scientists publish their findings. We also enjoyed learning that English is the international language of science. 


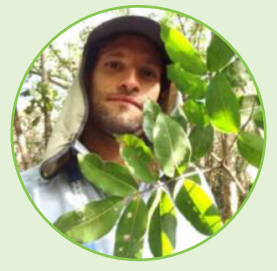

\section{AUTHORS}

\section{GABRIEL DAMASCO}

I am a Ph.D. Candidate at the Department of Integrative Biology, University of California Berkeley. I have studied plant diversity in the Cerrado and other tropical biomes for more than 15 years. My interests mainly lie in exploring tropical ecosystems, discover new species and catalog plants in poorly studied sites. During field expeditions, I love interacting with local people and getting to know their cultural history. Their historical knowledge represents an essential layer of biodiversity. *gdamasco@berkeley.edu

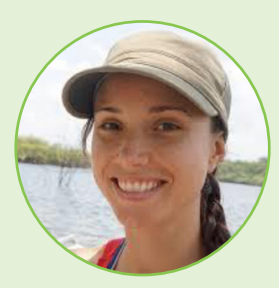

\section{CLARISSA FONTES}

I am a Ph.D. Candidate at the Department of Integrative Biology, University of California Berkeley. I am passionate about plant physiology, and my primary interests lie in unveiling how plants have adapted to tolerate dry climate. My work is based mainly in the Amazon region, but I have also worked for many years in the Brazilian Cerrado. I love doing fieldwork in the tropics, and after I finish my Ph.D., I will accomplish my dream of being a plant physiologist and a tropical scientist in Brazil.

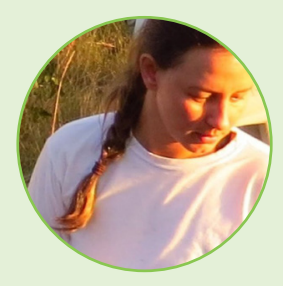

\section{RENATA FRANÇOSO}

I am ecologist teaching Plant Biology and Cerrado Ecology at the Federal Institute of Brasilia, Brazil. I am interested in understanding the drivers of species diversity and distribution at different spatial scales, as well as the effectiveness of conservation practices to maintain biodiversity in the Cerrado biome. Currently, I am studying how species and ecosystems are sensitive to climate change to guide environmental policies focused on landscape restoration.

\section{RICARDO HAIDAR}

I just finished my Ph.D. at the Department of Ecology, University of Brasilia. I have been studying plant diversity in the Cerrado for more than 20 years. In my doctoral dissertation, I investigated the ecological factors that drive the distribution of Seasonally Tropical Dry Forests in Brazil. I am currently working with reforestation projects that aim to recover the biodiversity and the natural ecosystems in the Brazilian Cerrado. 